\title{
The initial evaluation of performance of hard anti-wear coatings deposited on metallic substrates: thickness, mechanical properties and adhesion measurements - a brief review
}

https://doi.org/10.1515/rams-2019-0003

Received Jun 13, 2018; accepted Oct 04, 2018

\begin{abstract}
The demand for metallic materials of exceptional tribological performance is rapidly growing due to constant development of automotive, tool or implant industry. As great attention nowadays is being paid to the surfacemodified materials, there is a need of establishing reliable methods for evaluation of coated metallic alloys. In this paper, methods for thickness, adhesion and mechanical properties measurement of anti-wear coatings are considered. The importance of altering the mechanical properties of the coating with regards to its expected wear performance is also discussed. According to the numerous findings, it is reasonable to pay attention to the hardness and Young's modulus of the developed coating, as well as on the mismatch between its Young's modulus and the elastic modulus of the substrate material. Information provided in this paper has been thoroughly illustrated and enriched with our own experience in the field.
\end{abstract}

\section{Introduction}

The ever-increasing requirements that metallic materials should meet are the cause of the continuous development of new surface modification methods. The selection of adequate methods for evaluating new anti-wear coatings is a complex process in which numerous factors are of great importance. When assessing a newly developed coating, its planned application, the complexity of technological

\footnotetext{
*Corresponding Author: Magdalena Eępicka: Faculty of Mechanical Engineering, Department of Materials Engineering and Production, Bialystok University of Technology, ul. Wiejska 45 C, 15-351 Białystok, Poland; Email: m.lepicka@pb.edu.pl

Małgorzata Grądzka-Dahlke: Faculty of Mechanical Engineering, Department of Materials Engineering and Production, Bialystok University of Technology, ul. Wiejska 45 C, 15-351 Białystok, Poland
}

process and prospective need for optimization should be considered. Introduction to the market films which have not been thoroughly tested can carry not only many extra costs, but also negative business and social consequences. Hence, newly introduced coatings are much more rigorously tested than surface modification methods that have been approved for mass production many years ago. Therefore, an extremely important element of the research and development (R\&D) process of a coating is to establish its basic properties which are crucial from the view of its intended application. For example, in tribology-related applications, chemical composition and reactivity, wear performance and frictional properties of the coating are one of the key factors when the film remains under development, whereas its adhesion, thickness and repeatability of the deposition process are critical when the coating already is introduced to the market and its properties have previously been optimized.

Therefore, the number and nature of planned experiments depends strongly on the scope and type of planned applications of the newly introduced coating as well as on the current stage of its development. Some of the anti-wear coatings are characterized by high versatility and can be used in seemingly non-related branches of industry, e.g. manufacturing of cutting tools or synovial joints endoprostheses. In such case, it is important to develop the most comprehensive set of tests that will allow one to predict the performance of the coating under various operating conditions, and to decide whether it is possible to use the film under planned circumstances. Moreover, the coating development process can be accelerated with the use of finite element method (FEM) simulations and mathematical models that are used to predict the mechanical properties of the new thin films and reduce time that is necessary for the prototyping process [1]. These models usually require knowledge of basic properties of the coating, e.g. its Young's modulus, Poisson's ratio, fracture toughness, hardness, thickness and adhesion to the substrate [1]. In some cases, further data processing is required, which in 
combination with analysis of the findings obtained during experimental work will make it possible to determine the basic properties of the coatings with sufficient accuracy. These factors are the cause of the growing need for modern coating characterization methods.

The number of methods of thin films assessment is rapidly growing. Many specialized measurement methods are already available, yet the great number of new and highly sophisticated solutions is still to come. In this paper, methods for thickness, adhesion and mechanical properties measurement of anti-wear coatings are considered. The importance of designing mechanical properties of the coating with regards to its expected wear performance is also discussed.

\section{Thickness measurements}

In terms of tribological properties, there is a complex relationship between the thickness of the coating and its certain properties, e.g. internal stresses, adhesion to the substrate and hardness [1]. Although it seems like a simple matter to measure the thickness of the coating, it should be noted that thickness measurement can be implemented in a variety of ways: by geometric means, that is by measuring the distance between the surfaces of interphasal separation, by mass or by variety of indirect methods using the physical properties of the coating, e.g. electrical conduction or optical adsorption [2, 3]. The general guidelines for thickness measurement of thin films have been included in the standard ISO 2064:2004 [4].

The thickness of the coating determined by geometric methods is expressed in meters and their multiples [1] and does not consider the composition, nor density or microstructure of the coating [2]. An advantage of direct measurements is that they are made on the cross-sections of surface modified materials observed using widely available microscopic techniques [1]. As a rule, geometric measurements of coating thickness provide satisfactory results, but if the cross-section of the deposited layer is deformed or damaged as a result of the metallographic sample preparation process, it becomes problematic to determine the thickness properly [1]. Moreover, sometimes it is difficult to establish interphase boundary between the examined surfaces. Although there is a vast variety of methods available for measuring the thickness of thin anti-wear coatings (Figure 1), the most popular techniques are microscopic measurements made on cross-sections of the specimens, profilometric methods and the calotest method [1].

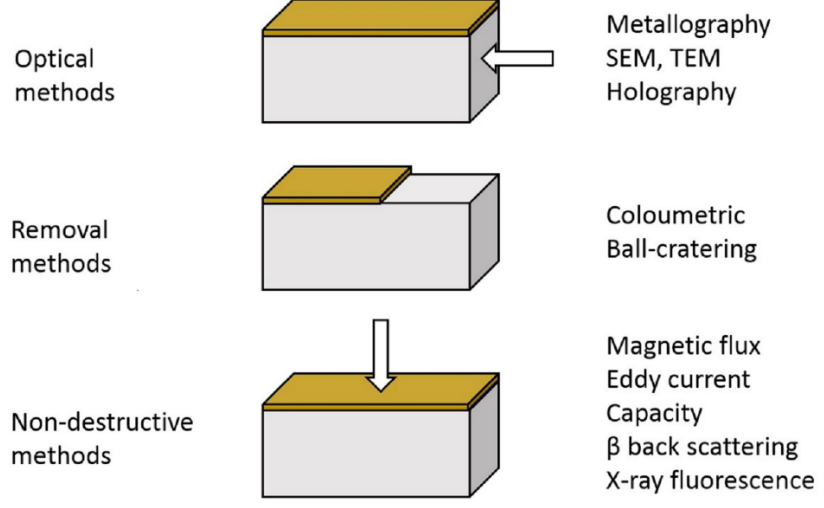

Figure 1: Optical, removal and non-destructive methods used for measuring the thickness of the anti-wear coatings.

In the profilometric method, thickness of the coating is defined by determining the difference in height between the bare surface of the sample and the coated area. Therefore, the deposition process has to be designed in the way that the artificial slip between the coating and the substrate is obtained $[1,2]$. The best results are achieved when the difference in height between the outer surface of the coating and the metallic substrate is greater than $1 \times 10^{-8}$ $\mathrm{m}$ [2]. The accuracy of the profilometric method depends on the roughness of examined surface $[1,2]$ and its planeparallelism [2].

In the calotest method, a rotating ball of known diameter is used to determine thickness of the coating $[1,5]$. As a result of frictional forces generated by rotating movements of the sphere, a coating and a substantial part of the underlying substrate are removed from the surface of the specimen. A spherical cavity is obtained in the test material, whereas worn traces formed on the surface of the sample are in the shape of concentric circles (Figure 2). To accelerate wear of the coating, abrasive agents, e.g. diamond paste can be used. In order to determine thickness of the coating, diameters of obtained traces have to be measured using a metallographic microscope. When thickness of a monolayer is measured, etchant can be used to visually reveal the coating-substrate interface [5]. The accuracy of the calotest method is estimated at $\pm 1 \times 10^{-7} \mathrm{~m}$ [5].

The advantage of the calotest method is its ability to adapt for both mono- and multilayer systems. If the thin film consists of multiple interlayers, the limitation of using the calotest method is the ability to distinguish individual interlayers and their thickness, which will allow to perform measurements by microscopic methods [1]. An undoubted advantage of the calotest is the ability to measure thickness of the coating in different areas of the sample and therefore determine the uniformity of the coating. 


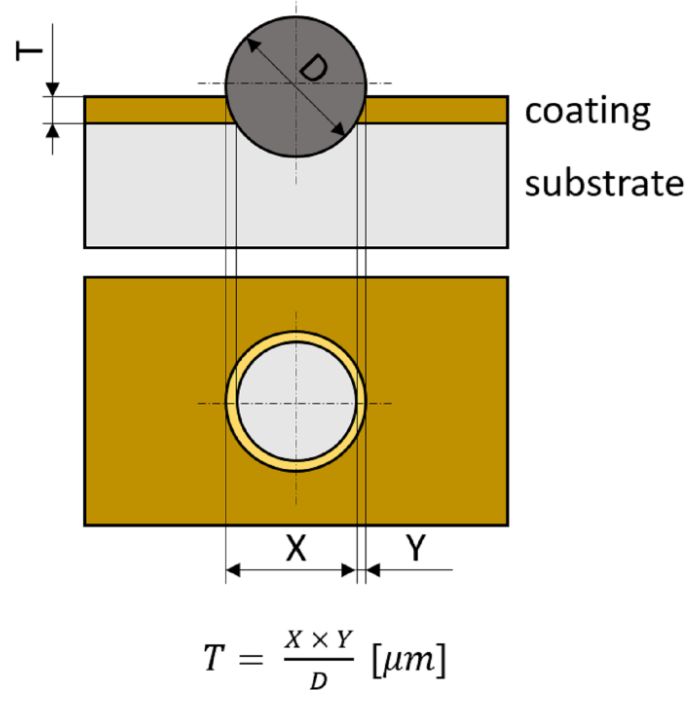

Figure 2: The principle of the calotest method (based on [6]); D the diameter of the ball used in the test, $X$ and $Y$ - diameters of the obtained scar, T - coating thickness.

However, in many cases the geometric thickness measurements, which do not even consider porosity of the films, is insufficient. In such cases, the mass thickness of the coating can be measured [2], which is usually expressed in grams per unit area, e.g. square meters. If necessary, it is possible to change the mass thickness to geometric thickness, although it is required to have knowledge of the density of the tested coating [2]. However, techniques applied in mass thickness measurements are sensitive to the presence of pores or discontinuities in the microstructure [2].

Methods for measuring thickness that are based on physical properties of the coating are, however, susceptible to accuracy of determination of the relationship between thickness of the coating and the analysed physical property [1]. In case of the electroconductive layers which are deposited onto insulating substrates, methods based on electric resistivity are used [1]. The simplest method to measure resistivity of the coating is the two-point method, in which resistivity of the deposited layer is determined by Ohm's law as a quotient of voltage and current [7]. To determine thickness of the coating, other methods based on e.g. electromagnetic, optical or acoustic properties can be used [1].

In case of thermo-chemical treatments, e.g. nitriding or carburizing, a common method of determining the thickness of a modified layer is to measure the thickness of the hardened layer of the specimen - the case depth [8]. To investigate the effective layer thickness, a series of hardness measurements in a perpendicular direction to the coating is made on the cross section of the sample (Figure 3). Based on the graphical representation of change in hardness it is possible to determine the thickness of layer that has been hardened due to applied surface modification process [9]. Typically, case depth is the depth up to which the hardness of the modified layer is greater than hardness of the substrate by $33 \%$ or more [10]. A detailed methodology for measuring the effective thickness of a modified layer is given in the ISO 2639:2005 standard [9].

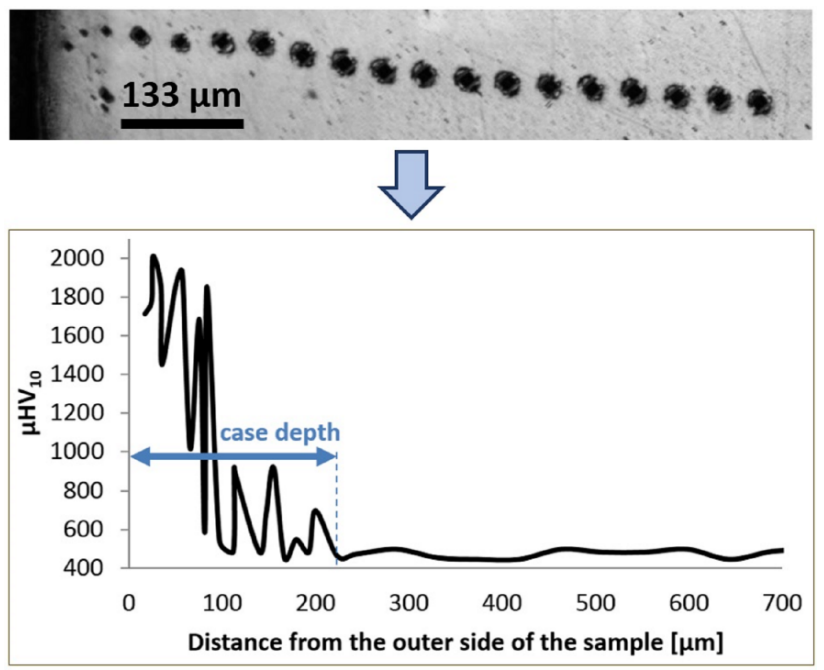

Figure 3: Example of the case depth measurement - plasmanitrided martensitic stainless steel. As it can be seen, the case depth is observed up to ca. $220 \mu \mathrm{m}$ from the outer side of the sample.

In case of the anti-wear coatings, mainly microscopic techniques are used to determine thickness of the film [11]. Though microscopic evaluation of the coating thickness is characterized by high accuracy, one should remember that the quality of the measurement depends not only on the quality of the sample itself, its preparation method or the resolution of the microscope, but also on the substrate material or even the coating that is under evaluation. An example of the coating thickness measurement taken by microscopic methods is given in Figure 4.

TiN coating presented in Figure 4 was deposited on Ti6Al4V ELI alloy by PVD methods. As presented in the picture, though scanning electron microscope (SEM) allows to obtain greater magnification of the sample than the measuring laser confocal microscope (CLSM), the picture quality obtained by SEM is poor in the means of coating thickness measurement. The hardware capabilities of the tabletop SEM used to take the presented picture were insuffcient in terms of establishing a sharp image of the interfacial boundary between the substrate and the film. 


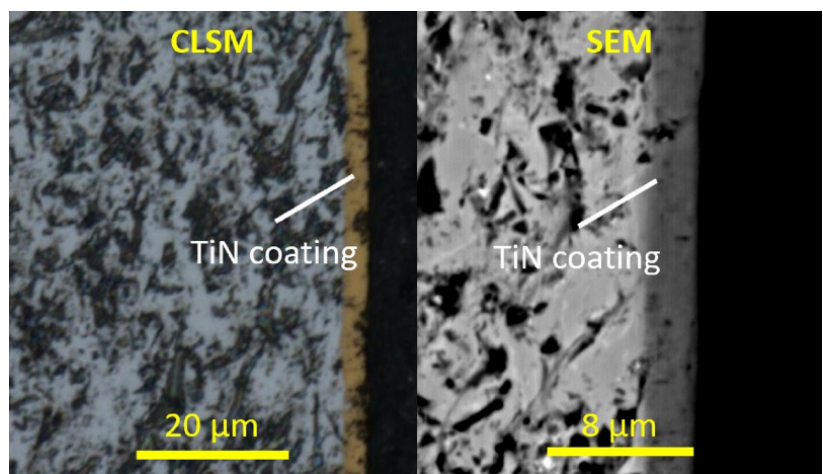

Figure 4: Measurement of PVD TiN coating thickness deposited on Ti6Al4V ELI biomedical titanium alloy (own research): left - confocal laser measuring microscope (CLSM), right - scanning electron microscope (SEM). Blurriness of the titanium nitride coating at the picture obtained by SEM can be seen.

As shown in the given examples, to obtain credible results from thickness measurements of the coatings and modified layers, it is important to choose the measuring technique properly. Since the commonly used methods can be sensitive to density, chemical composition, microstructure or the crystallographic orientation of the coating, thickness measurements of the same specimen made by different techniques may exhibit significantly different results. For this reason, the optimal solution is to adapt a research methodology that is the most popular for given coating. This is of great practical importance, because it allows researcher to compare his results with findings given in the works by other authors.

\section{Nanoindentation and its importance in wear control of hard coatings}

Since its introduction in 1992 [12], the Oliver's and Pharr's method for hardness and elastic modulus testing of engineering materials has attracted a lot of scientists and became one of the most popular techniques that are used to establish the mechanical properties of the materials in microscale. Although this indentation method has been initially designed for analysing bulk materials [13], the availability of high-resolution measuring equipment, as well as the ability to determine the mechanical properties of the material directly from the load-displacement curve, without the need of imagining the impression obtained as a result of the applied load, have contributed to the growing popularity of this technique in measuring the mechanical properties of the materials in nano- and microscale. Currently, the Oliver-Pharr method is used to measure the basic mechanical properties of the coatings that are at least 1 $\mu \mathrm{m}$ thick, but for comparison purposes it can be used also for the coatings with thickness of up to a few nanometres [14].

The main objective of the nanoindentation measurements is to determine the Young's modulus and hardness of the examined material based on the experimentally determined loading force and the corresponding displacement of the indenter. Schematic representation of the data collected during the nanoindentation test performed using the Berkovich indenter, the load-displacement curve, is given in Figure 5.

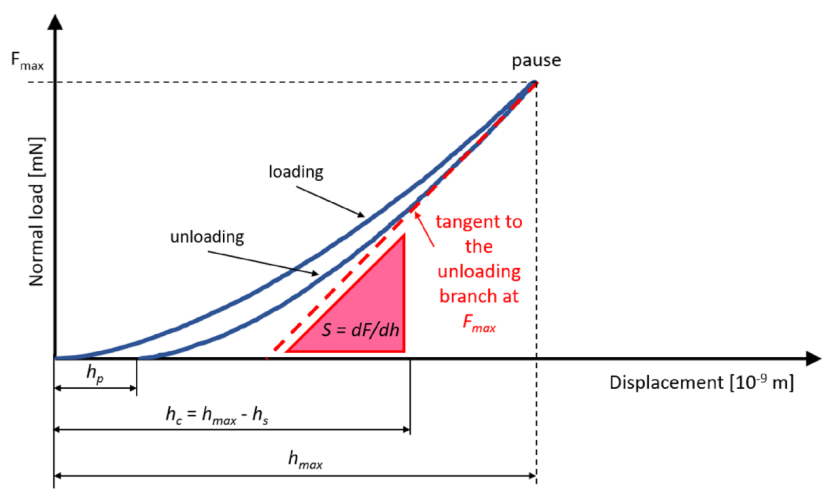

Figure 5: Schematic representation of the load-displacement curve obtained in the nanoindentation tests. In general, if the smooth and continuous loading and unloading curves are obtained, no cracking or discontinuity in the coating can be seen. Moreover, if no displacement is seen during the pause time, the coating does not creep.

In the classic Oliver-Pharr method, in which the triangle-based pyramid diamond tip is used - the Berkovich indenter [14] - the applied force and the displacement of the indenter are recorded from zero to a certain maximum, and after reaching the maximum load value, the load is reversed and reduced at a specific pace from maximum to zero [15]. In contrast to conventional hardness measurement techniques, the obtained impression is often not big enough to measure its externals using optical microscopy methods. Therefore, the projected contact area is determined based on the indenter displacement. Given the vertical displacement of an indenter and the tip geometry it is possible to indirectly measure the contact area A that is obtained when applying maximum normal load $F_{\max }[14]$ :

$$
A=F\left(h_{c}\right),
$$


where $h_{c}$ is the depth along which contact is made between the indenter and the specimen, as calculated from [14]:

$$
h_{c}=h_{\max }-h_{s} .
$$

It is estimated that $h_{\max }$ is the maximum displacement of the indenter under load $F_{\max }$, while $h_{s}$ is the elastic deflection of the material in the contact periphery (sink-in) [16]. The $h_{s}$ is given by [14]:

$$
h_{s}=\epsilon \frac{F_{\max }}{S},
$$

where $\epsilon$ is a constant that depends on the geometry of the indenter and $S$ is the slope of the elastic unloading curve $(d F / d h)$. For Berkovich indenter, the $\epsilon$ value always equals $0.75[12,14,15]$. The choice of this value is justified by the impact of the elastic substrate on the effective contact area of the indenter-examined material interface [17].

Knowing the value of the contact area $A$, hardness of the analysed material can be given as [14]:

$$
H=\frac{F_{\max }}{A} .
$$

Note that hardness of the analysed material is calculated based on the contact area $A$ that is obtained under maximum load $F_{\max }$. It is of high importance especially in the case of elastic materials, because there can be statistically significant difference between their hardness determined by nanoindentation method, using the loaddisplacement curve, and the hardness established using traditional methods that are based on measurements of externals of the impressions. For elastic materials, the elastic recovery during unloading can affect significantly the area of the residual hardness impression. Nevertheless, it is claimed that the elastic recovery effect on the findings should be taken into account only for materials characterized by extremely small $E / H$ values [14].

In practice, when the Berkovich indenter is used, the projected contact area $A$ is given by [15]:

$$
A=3 \sqrt{3} h_{c}^{2} \tan ^{2} \theta .
$$

After simplifying the equation (5) and taking into account the tip half angle $\theta=65.27^{\circ}, A$ can be calculated from [15]:

$$
A=24,494 h_{c}^{2} \approx 24,5 h_{c}^{2}
$$

while the hardness $H$ can be expressed as [15]:

$$
H=\frac{F_{\max }}{24,5 h_{c}^{2}} .
$$

The original Berkovich indenter with face angle of $65.03^{\circ}$ was designed in such a way that in the conventional hardness measurements its contact area to the impression depth ratio was the same as in the Vickers hardness measurements. However, in the nanohardness measurements, the measured hardness is linked to the stress applied un$\operatorname{der} F_{\max }$. Due to that, the measured hardness value cannot be directly converted to the Vickers scale. Therefore, for the nanohardness measurement purposes, the face angle of the indenter was slightly modified and the angle of $\theta=65.27^{\circ}$ was assumed as the correct face angle of the Berkovich indenter [15].

Assuming that during unloading of the material only elastic deformation occurs, Sneddon [18] developed a relationship between the displacement $h$ and the load $F$ in the region of contact between the axisymmetrical measuring tip and the material that is being tested. Continuing his work, Pharr et al. [19] as well as Oliver and Pharr [14] proposed the following relationship between the reduced Young's modulus $E$ and $S$, defined as the tangent to the upper part of the unloading curve:

$$
S=\beta \frac{d F}{d h}=\beta \frac{2}{\sqrt{\pi}} E \sqrt{A},
$$

where $\beta$ is a dimensionless geometric correction factor. Its purpose is to take into account the stiffness deviation during loading that results from the use of the pyramidshaped indenters. In the original hardness and Young's modulus measurement technique, the value of $\beta$ correction factor equalled 1 . Nevertheless, multiple papers published by other authors showed that, depending on the reason, the actual $\beta$ value that should be used during measurements varies between 1.02 and 1.08 [15]. Nowadays, the most commonly chosen value of $\beta$ correction factor is 1.034, as proposed by King [20]. The reduced Young's modulus value $\mathrm{E}$ can be expressed by the following relationship [14]:

$$
E=\frac{1}{\frac{1-v_{s}^{2}}{E_{s}}-\frac{1-v_{i}^{2}}{E_{i}}}
$$

The following formula takes into account the fact that elastic deformations take place not only in the analysed material sample, which is characterized by its Young's modulus $E_{s}$ and Poisson's ratio $v_{s}$, but also in the diamond tip with the elastic modulus $E_{i}=1140 \mathrm{GPa}[14,21]$ and Poisson's ratio $v_{i}=0,07[14,21]$. Although equation (9) was developed for purely elastically deforming materials [19], further studies have shown that it can be successfully applied in elastic-plastic materials, while the slight deviations from the axisymmetry of the indenter have no significant effect on the obtained findings [14].

According to ISO 14577:2015 [22], the mechanical properties evaluation can be considered as done in the nanoscale if the vertical displacement of the tip during 
dwelling does not exceed $2 \times 10-7 \mathrm{~m}(0.2 \mu \mathrm{m})$. Moreover, it is assumed that in order to reduce measurement uncertainty that arises from the surface roughness below $5 \%$, the displacement of the indenter $h$ should be at least 20 times the Ra value. However, the basic difficulty in nanoindentation measurements results from the fact that the maximum displacement of the tip, $h_{\max }$, should not exceed $10 \%$ of the examined coating's thickness [15]. It is believed that the greater is the vertical displacement of the diamond tip in the coating, the bigger is the influence of the substrate on the obtained findings [13]. As an effect, the measurement can be distorted by the substrate influence. Nevertheless, as the modern protective coatings are becoming extra-thin, the $10 \%$ rule can be applied for a limited number of cases. Due to that, numerous modifications of the classic OliverPharr method have been developed [23]. However, Ni and Cheng [24] as well as Solis et al. [25] have shown that the $10 \%$ rule can be applied also when measuring mechanical properties of the hard coatings that were deposited on relatively soft substrates. On the other hand, FEM (finite element method) calculations have shown that for soft coatings deposited on hard substrates, the discussed safe value can be increased even up to $30 \%$ [15].

In general, it is assumed that at lower indentation depths, an increase in hardness can be initially observed, which is associated with the elastic deformations of the indenter and its bluntening [15]. After performing a sufficiently great number of measurements with the increasing load value and plotting the hardness-depth graph, part of the plotted curve should represent plateau, which corresponds with the actual hardness of the examined coating [26]. Decrease or increase in hardness that follows the plateau indicates that the influence of the substrate is observed $[15,25]$. Therefore, the measured hardness of the coating is the average hardness taken from the plateau region.

Though hardness is considered as one of the main factors that determine the wear performance of most engineering materials, identification of deformation mechanism of the coating under load as well as determination of its Young's modulus value are crucial for establishing anti-wear performance of a ceramic coating. If hardness and elastic modulus of the film are known, it is possible to determine its strain to failure, denoted as hardness to elastic modulus ratio $H / E$ [27].

The $H / E$ quotient originated from the plasticity index $\Psi$, which was devised for static contacts to estimate the surface roughness at which no plastic deformation of the roughness asperities is present [28]. The plasticity index $\Psi$ is given by equation [28]:

$$
\psi=\frac{E}{H_{1}} \sqrt{\frac{\sigma}{R}}
$$

where $E$ is the reduced Young's modulus, $H_{1}$ is the hardness of the softer material, $R$ is the typical radius of a surface asperity and $\sigma$ is the standard deviation of the roughness asperity height distribution. It is concluded that when $\Psi>1$, the surface asperities are plastically deformed [29], but when the index $\Psi<0.6$, elastic deformation of the asperities only takes place. Inverting the $\mathrm{E} / \mathrm{H}$ ratio gives $\mathrm{H} / \mathrm{E}$, where the greater the $\mathrm{H} / \mathrm{E}$ ratio is, the more elastic is the material in rough contacts [29]. When the considered coating is of high hardness, $\mathrm{H} / \mathrm{E}$ value of approx. 0.1 is the indicator of high wear performance of the modified surface [30].

The prognosis of the coating wear resistance based on its $H / E$ ratio can be justified by the fact that the tribological wear of materials is caused mainly by their plastic deformation [31]. Studies conducted by the other authors show that the $\mathrm{H} / \mathrm{E}$ ratio is proportional to the elastic (reversible) work $W_{e}$ to total work $W_{t o t}$ ratio, namely $H / E \sim W e / W_{t o t}$ [31]. As a consequence, if two materials are deformed, a greater fraction of work is consumed for plastic deformations by the material of small $H / E$ [31]. What is more, the plastic deformation observed during nanoindentation tests, denoted as the $h_{p}$ to $h_{\text {max }}$ ratio, is associated with the strain to failure ratio, as given in equation [32]:

$$
\frac{h_{p}}{h_{\max }}=\frac{W_{t o t}-W_{e}}{W_{t o t}} .
$$

According to equation 3.11, the greater is the plastic deformation of the material, the more severe wear is expected. Due to that, greater wear is observed if the coating has a low $H / E$ ratio [31].

Another important parameter that enables to describe wear properties of surface modified materials accurately is the plasticity index, given as $H^{3} / E^{2}$ [25]. It is believed that in sliding contact, wear of materials is intensified by material deformation in the coating/substrate interface, while the high $\mathrm{H}^{3} / \mathrm{E}^{2}$ value ensures satisfactory coating strength [30]. The $P_{y}$ load, which causes plastic deformation of the rigid ball in the tribological contact with the plastic-elastic coating, is highly dependent on the hardness $H$ and the reduced Young's modulus $E$ of the coating:

$$
P_{y}=0.78 r^{2}\left(\frac{H^{3}}{E^{2}}\right),
$$

where $r$ is the radius of the sphere that is in contact with the flat surface. Due to that, the $H^{3} / E^{2}$ ratio is an important criterion of the coating resistance to plastic deformation in ball-on-flat or ball-on-disc contact. High value of 
the $H^{3} / E^{2}$ ratio is associated also with coating's resistance to brittle fracture, as presented in the work by Musil and Jirout [33].

In general, in most of the engineering applications, the greater are the $H / E$ and $H^{3} / E^{2}$ ratios presented by the coating, the better should be its wear performance [25, 27]. Low Young's modulus is favourable especially if it is possible to adapt it to the elastic modulus of the underlying surface. Low value of Young's modulus promotes uniform stress distribution at the coating-substrate interface, what allows to reduce wear of the considered material [34].

However, adjusting the stiffness of the components is particularly difficult when depositing hard ceramic coatings, which are typically characterized by the three to four times greater Young's modulus than the metallic substrate that is supposed to be protected, e.g. steel [27]. Due to that, some of the authors claim that the $E_{\text {coating }} / E_{\text {substrate }}$ ratio represents better the anti-wear capacity of surface modified materials than the aforementioned ratios. According to Musil and Jirout [33], the $E_{\text {coating }} / E_{\text {substrate }}$ ratio is associated with the susceptibility of the hard and superhard coatings to cracking. As stated by the authors, if the ratio of the hard coating's Young modulus to the soft substrate's elastic modulus does not exceed 1.3, normal load causes not only plastic deformation of the coating, but also its brittle cracking [33].

According to the study by Huang et al. [35] on the TiN and TiAlN coated copper, high speed steel and sintered carbides, the greater is the mismatch between the coating and substrate Young's modulus, i.e. the more $E_{\text {coating }} / E_{\text {substrate }}$ value differs from 1, the greater is the measured wear. What is more, the authors claim that the $E_{\text {coating }} / E_{\text {substrate }}$ value affects also the coefficient of friction of the tribological pair observed during wear tests. The WC-Co substrate, which is characterized by the high load-bearing capacity, was characterized by the greatest wear resistance amongst all analysed samples for both TiN and TiAlN coatings [35]. The influence of $E_{\text {coating }} / E_{\text {substrate }}$ ratio on wear resistance of the coated materials was considered also in the works by AvelarBatista et al. [36] or Eępicka et al. [37]. According to AvelarBatista et al. [36], amongst coatings: (Ti,Al)N, TiN and CrN deposited on AISI H13 steel, the greatest wear resistance was achieved by the (Ti,Al)N coating, which was characterized by lowest Young's modulus mismatch with the substrate $\left(E_{\text {coating }} / E_{\text {substrate }}=1.6\right)$.

Though there are many factors associated with the mechanical properties of substrate and coating that affect wear resistance of coated materials, one should always remember that wear performance of the material depends not only on the values that can be measured in nanoindentation tests. If wear of the considered material is affected by chemical-related factors, e.g. interactions between the tested material and air, segregation of wear products or lubrication, the discussed ratios: $H / E, H^{3} / E^{2}$ and $E_{\text {coating }} / E_{\text {substrate }}$ should not be considered as the only determinants of wear properties of the coating $[37,38]$. Some of the coatings, e.g. DLC, undergo also the wear-induced phase transformation $[25,37]$. Due to that, caution is recommended when planning to interpret wear test results based only on the ratios described in this paper.

\section{Adhesion of the anti-wear coatings to the metallic substrates}

According to Holmberg and Matthews [10], adhesion is the ability of the coating to maintain contact with the substrate under specified operating conditions. Therefore, adhesion is one of the most important attributes of the surface modified systems, as it determines the durability and reliability of the finished products. When coating is chipping or delaminating, it is unable to fulfil its protective function. As a result, substrate becomes exposed to aggressive external factors, e.g. corrosive gases and liquids, abrasive particles or elevated operating temperature [39]. Long-term exposure to harmful agents can result in loss of functional properties of the material, significantly limit service life of the finished product and, in extreme cases, even cause its premature failure. For this reason, there is a justified need to find reliable methods for assessment of adhesion of anti-wear coatings to the metallic substrates.

There are four main mechanisms of the coating adhesion [39]: (a) interfacial adhesion, which is oriented around a known and well-defined interfacial plane [40]; (b) diffusion adhesion, in which the coating and the substrate atoms are mixed, forming a diffusion area of a certain thickness [40, 41]; (c) adhesion of the intermediate layers, that differ significantly in chemical and mechanical properties, which are used to separate the functional coating from the substrate and to enhance adhesion of the antiwear layer and (d) mechanical adhesion, which results from the surface topography of the substrate and its roughness [40, 42]. Furthermore, adhesion of the anti-wear coating to the metallic substrate is influenced by many other factors, e.g. applied surface modification method, thickness of the coating $[43,44]$, machining and other methods of preparation of the substrate's surface prior to deposition [45], interfacial defects and other imperfections [39], 
Young's modulus mismatch between the substrate and the coating [46] as well as thermal expansion coefficients of the substrate and the coating [47].

There is a number of both destructive [1] and nondestructive methods for measuring the adhesion of hard coatings to the metallic substrates [48]. In practice, however, methods that are based on mechanical properties measurements are the most commonly used [48]. The most common methods for determining the adhesion of antiwear coatings are relatively simple to implement, while the level of approximation of the obtained results is sufficient in practical applications.

One of the simplest methods for adhesion evaluation is the pull-off method [1]. With the use of an epoxy glue, metallic rods with diameter of $25 \mathrm{~mm}$ are mounted to the surface of the coated materials [40]. When the glue is cured, a normal or shearing force is applied to the outer tip of the rod by the means of a mechanical load system [10]. The value of the adhesion is the load which causes delamination of the coating from the substrate [10]. A significant difficulty in proper application of this type of test is the maximum tensile strength of the used adhesive - for high performance adhesives, typical tensile strength of the obtained bonding does not exceed $100 \mathrm{MPa}$ [1]. Since the original test was designed for the oxide layers and thermally sprayed coatings, which are characterized by relatively low adhesion strength to the substrate, tensile strength of the used adhesives was sufficient [1]. However, in the case of anti-wear coatings obtained by CVD and PVD methods, the adhesion strength of the coating to the substrate is usually higher than the tensile strength of organic adhesives [1] Therefore, in specific cases it is acceptable to force initiation of the coating cracking process even before starting the pull of test [1]. Since the pull off method is characterized by high dispersion of results, its validity in testing of hard coatings is considered to be disputable [49].

Another popular method for measuring the adhesion of hard coatings to the metallic substrates, the four-point bending test [1, 38, 39], was introduced in 1989 by Charalambides et al. [50]. The four-point bending test is used in evaluating the fracture toughness of coatings used in medical applications [40]. In this method (Figure 6), the sample is oriented in such a way that the coating cracks due to the applied load and the resulting tensile stress [1]. Usually coating cracking throughout its thickness in a direction perpendicular to the transferred stresses is observed [1]. In order to determine the value of the breaking stress, the test can be repeated several times using stepwise increasing loads, followed by optical or electron microscopic observations of the surface [1]. However, it is a time-consuming method affected by error which is caused by necessity of mounting sample each time in test apparatus and generating increasing tensile forces in order to observe cracking of the coating [1]. Due to that, some systems are equipped not only with an optical microscope, which allows to conduct real-time sample observations, but also with the acoustic emission sensors (Figure 6). By detecting the vibrations and sounds generated by the coating cracking, the acoustic emission sensors are able to detect stress at which failure of the coating starts [1]. Simultaneous usage of two types of sensors, optical and acoustic emission, allows to exclude acoustic emission noises originating from, for example, the deforming supports [1]. The tensile stress at which the first cracks appear is the resistance of the coating to cracking, which corresponds with a sudden increase of intensity of sound emission signal [1]. As tensile stress increases, the coating starts intensively flaking - it is the measure of the adhesion strength of the coating to the substrate [1]. The use of mathematical methods allows also to determine stress at which adhesive or cohesive fracture of the coating starts [1].

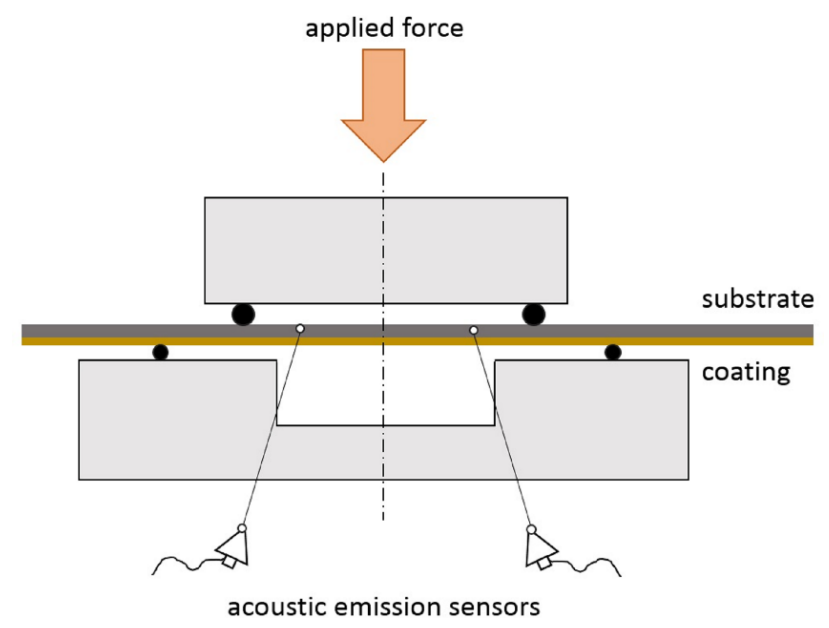

Figure 6: Schematic representation of the four-point bending test (based on [1]).

The four-point bending test is designated mainly for brittle coatings, which are characterized by fracture toughness significantly lower than the adhesion of the coating to the substrate [1]. In case of the ductile coatings, the plastic deformation can be observed instead of cracking, although it is also possible to observe delamination or peeling of the coating as well [1]. On the other hand, the coatings of exceptional adhesion to the substrate will be characterized by almost perfectly perpendicular cracking to the stress propagation direction as well as by segmentation of the coating between cracks, but no cracking at the interphasal boundary will be observed $[1,38]$. For this rea- 
son, numerous modifications of the classic Charalambides et al. [50] method have been proposed, for example, by using a stiffener of the top plane of the hard coating [39], sandwich specimens [39,51], movable platens [39] or introducing notches in the coating prior to the test $[39,40]$.

However, the most popular method for measuring adhesion on the anti-wear coatings [40] undoubtedly is the scratch test, which was introduced in the 1970s for assessing properties of PVD and CVD coatings [1]. In a typical scratch test, a Rockwell diamond indenter with a $0.2 \mathrm{~mm}$ tip radius and $120^{\circ}$ cone angle [52] is pulled over the surface of the coated substrate with an increasing normal load $[1,51]$. As a result, the stylus makes a scratch on a tested material (Figure 7). Deformation of the surface is observed [1] due to superposition of stress generated on the interphasal boundary between the metallic substrate and the ceramic coating as well as in the coating itself. As a result of plastic and elastic deformation of the material, various deformation modes of the coating are observed [40]. A typical scratch test is continued until total failure of the coating and exposure of the substrate is observed $[10,39,40]$. On the basis of the acoustic emission signals, changes in friction force or microscopic observations the so-called critical loads can be determined [40], which can be attributed, for example, to the appearance of the first cracks in the coating, its chipping or exposure of the substrate [10]. Acoustic emission signals are used mainly to detect first signs of damage induced by applied load, e.g. cracking, tangential force measurements - to determine critical loads for ductile coatings, while microscopic observations are performed to identify deformation mechanisms for all types of the coatings [39]. Critical loads are usually denoted as $L_{c x}$, where $x$ is the labelled index, e.g. $L_{c 1}$ - deformation of a cohesive nature.

As aforementioned, as a result of an increasing load, the elastic and plastic deformations appear on the sample surface. In the case of hard ceramic coatings, cracking takes place in several stages. During the typical scratch test, three main deformation mechanisms of the coating can be observed [53]: adhesive, cohesive or mixed cracking. Cohesive cracks appear typically as a result of accumulation of the tensile stresses in the front and in the rear of the pulled indenter [54]. When the hard coating of a relatively high Young's modulus is tested, stresses that are generated in the front of the moving indenter are of compressive nature [55]. However, if the substrate is quite ductile, its plastic deformation in the front of a diamond stylus takes place. As a result of the deformation of the substrate material, bending action of the coating starts. In effect, cohesive, transverse semi-circular cracks appear in the coating. As those cracks usually form in front of a mov- ing diamond tip, they facilitate the process of further deformation of the coating and its buckling [56]. If the coating is strongly buckled, loss of its adhesion to the substrate is soon observed. Adhesive cracks usually arise when the compressive stresses that are generated in the coating due to its scratching reach a certain critical value [53]. The local delamination and chipping of the coating are one of the most important effects of deformation, because those are a visible proof of the coating adhesion loss to the substrate [53].

However, it should be emphasized that the interpretation of the results obtained in the scratch tests is a quite difficult issue due to the possibility of the coexistence of various deformation mechanisms [52]. In the literature it is often stressed that the findings obtained in the scratch tests strongly depend on both the assumed test conditions and the internal parameters of the coating and the substrate. In many cases, the influence of many independent factors on the findings makes it impossible to directly compare results between the examinations conducted in different research groups [55]. It should also be considered that the same coating deposited on different substrates can differ in thickness considerably [55]. Among other things, due to complexity of the factors that affect results of the scratch tests, findings obtained by this technique are only an approximate of the coating adhesion and should be used only for comparison purposes, so that a coating of a "good" or "satisfactory" adhesion to the substrate can be identified [57]. Schwarzer et al. [58] suggest that due to inability to predict results of the scratch tests based on a given load or selected radius of the tip, it is reasonable to conduct further research into selecting scratch tests parameters that will be tailored to the intended applications of the coating.

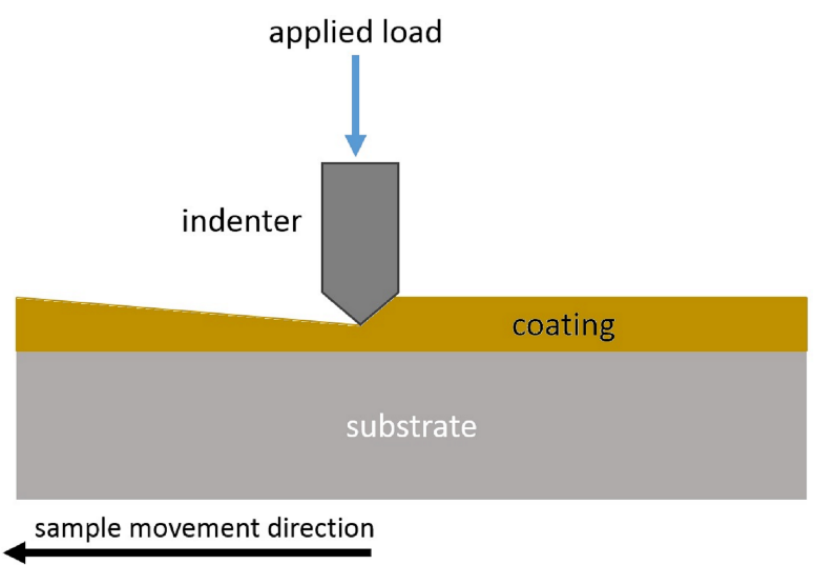

Figure 7: Schematic representation of the scratch test (based on [48]). A Rockwell C indenter is pulled over the surface of the sample with the increasing normal load. 
Table 1: Critical scratch test experimental variables (based on $[55,56,58,60-62]$ ).

\begin{tabular}{cc}
\hline Measurement parameters & Internal parameters of the sample \\
\hline Loading rate & $\begin{array}{c}\text { Mechanical properties of the substrate (Young's modulus, hardness) } \\
\text { Indenter transverse speed }\end{array}$ \\
$\begin{array}{c}\text { Properties of the coating (Young's modulus, hardness, thickness, internal } \\
\text { stress) } \\
\text { Indenter tip radius } \\
\text { Coefficient of friction } \\
\text { Design of the measuring device }\end{array}$ & Surface roughness \\
\hline
\end{tabular}

Table 2: Standard scratch adhesion test parameter values (PLST mode) (based on [52]).

\begin{tabular}{ccc}
\hline Standard & ISO $\mathbf{1 0 7 1 - 3}$ & ASTM C1624-05 \\
\hline Coating thickness & $<20 \mu \mathrm{m}$ & from 0,1 to $30 \mu \mathrm{m}$ \\
Preload & $1 \mathrm{~N}$ & $1 \mathrm{~N}$ for $L_{\max }<10 \mathrm{~N} ;$ \\
& & $5 \mathrm{~N}$ for $L_{\max }>20 \mathrm{~N}$ \\
Loading rate & $100 \mathrm{~N} / \mathrm{min}$ & $10 \mathrm{~N} / \mathrm{min}$ for $L_{\max }<20 \mathrm{~N} ;$ \\
& & $100 \mathrm{~N} / \mathrm{min} \mathrm{for} L_{\max }>20 \mathrm{~N} ;$ \\
& & $\operatorname{minimum~} 5 \mathrm{~N} / \mathrm{min}$ \\
& $10 \pm 0,1 \mathrm{~mm} / \mathrm{min}$ & $10 \pm 0,1 \mathrm{~mm} / \mathrm{min}$ \\
Rate of the horizontal displacement & & \\
of the sample & Rockwell C & Rockwell C \\
Indenter type & $R a<0,5 \mu \mathrm{m}$ & $R q<1 \mu \mathrm{m}$ \\
Surface roughness & - & $H V>5 \mathrm{GPa}$ \\
Coating hardness & 5 & 5 \\
Minimum number of repetitions & $22 \pm 2^{\circ} \mathrm{C}$ & $20 \pm 5^{\circ} \mathrm{C}$ \\
Temperature & $50 \pm 10 \%$ & $50 \pm 10 \%$ \\
Relative humidity & &
\end{tabular}

Although results obtained in the scratch tests are affected by many factors (Table 1), the mechanical properties of the substrate and the coating are believed to have the greatest influence on the findings of the tests conducted using a Rockwell indenter [56]. As shown in Figure 8, if the soft coatings are deposited on soft substrates, only plastic deformation of the examined material is observed. Typically, there is no cracking or chipping of the coating. However, in the case of hard coatings applied on soft substrates, cracking of the coating in the perpendicular direction to the surface is often observed. If those cracks reach the coating-substrate interface, they may propagate further in this plane. Typical deformation pattern of the hard antiwear coatings that can be observed in the scratch tests is shown in Figure 9. According to Holmberg et al. [59], when the diamond tip is pulled over the surface of the coated substrate with the increasing normal load, the following types of damage are typically observed: (a) angular cracks, (b) parallel cracks, (c) transverse semi-circular cracks, (d) thin film chipping, (e) coating spalling and (f) coating break-through.
Currently, there are multiple international standards that describe the methodology of scratch tests applied for various types of coatings, e.g. polymer films or paints [52]. However, the greatest practical significance is observed for tests conducted on hard ceramic coatings according ISO 20502 and ASTM C1624-05 [52]. These standards are used e.g. when evaluating surface-modified materials for medical applications. Selected parameters of scratch tests conducted in the progressive loading mode (PLST - progressive loading scratch test) in accordance with aforementioned standards are given in Table 2. As it can be seen, these standards are characterized by vast variety of applications as they make it possible to conduct research for coatings that significantly differ in thickness - for example, the ASTM standard can be used for coatings with thickness of up to $30 \mu \mathrm{m}$ [52]. Some of the damage modes determined based on the ISO or ASTM standards [52] are given in Table 3. 

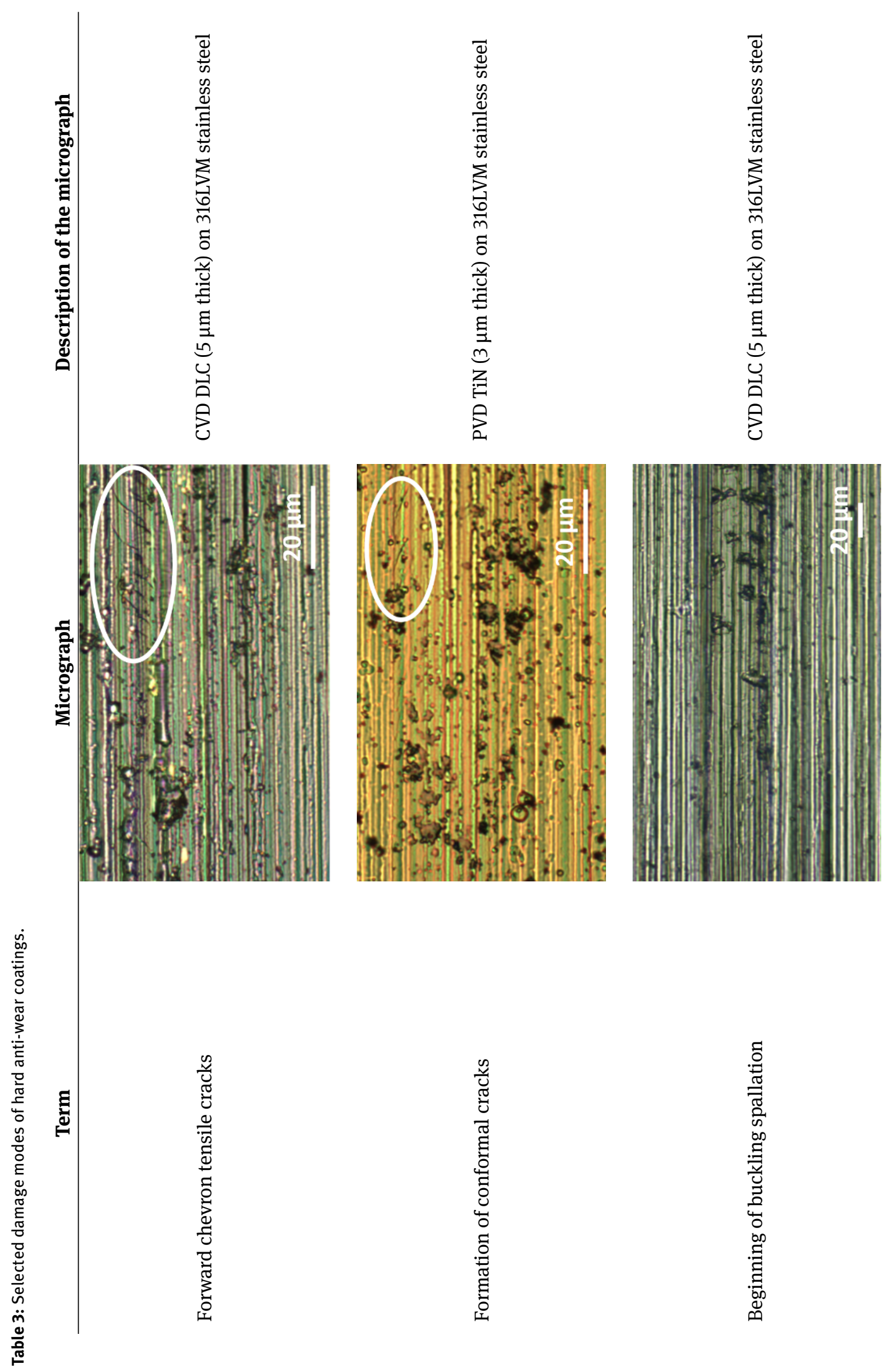

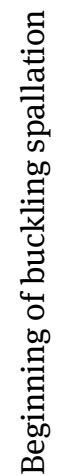




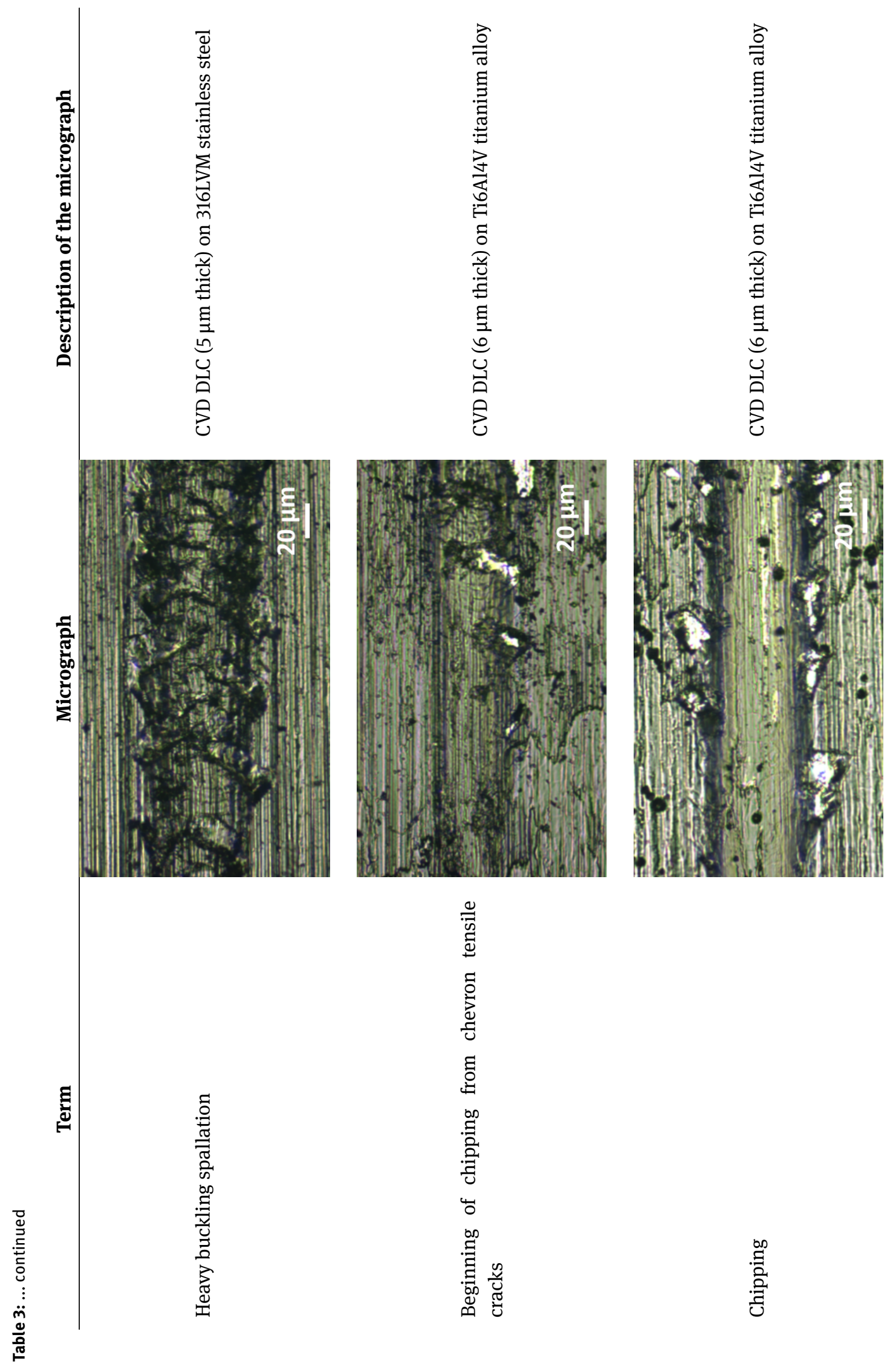




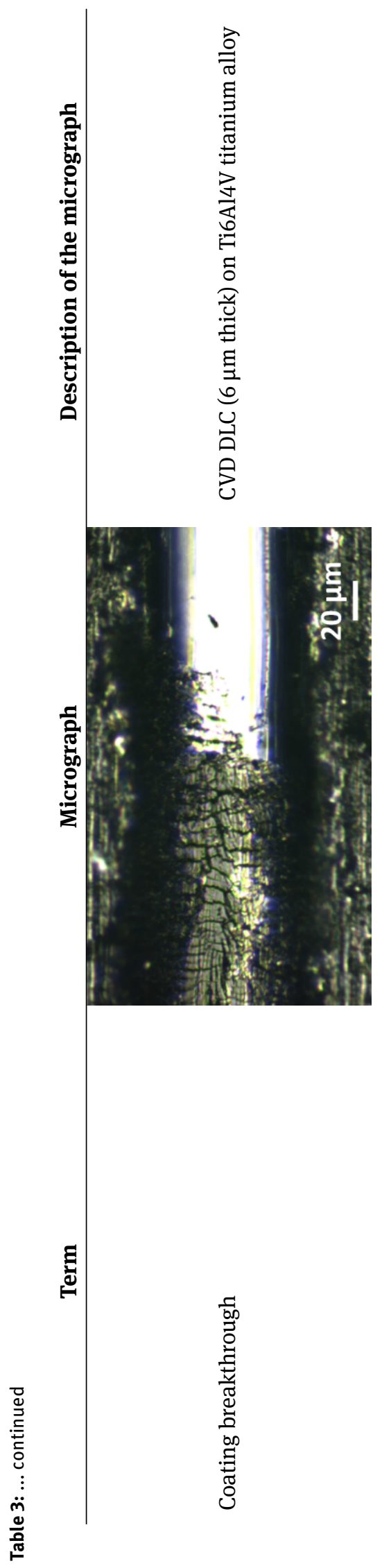




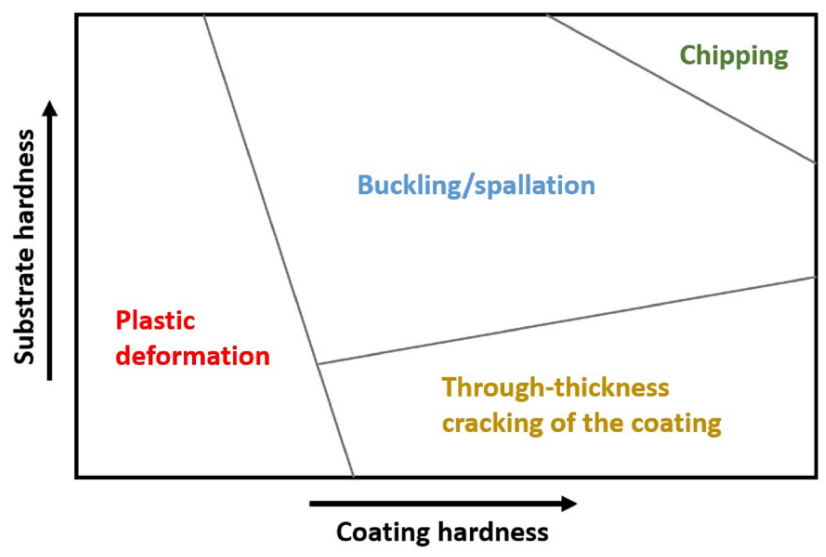

Figure 8: Schematic representation of main coating damage modes as a function of coating and substrate hardness (based on $[56,63]$ ).

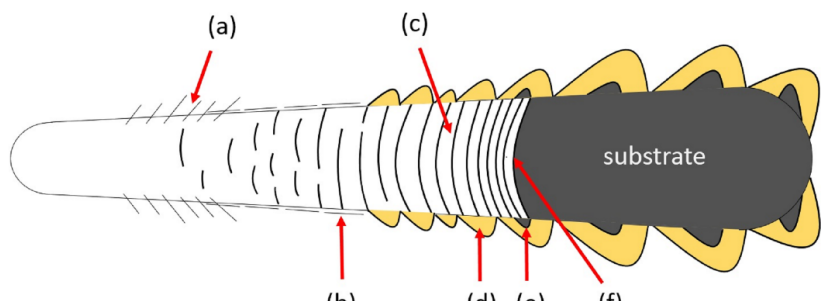

(b)

(d) (e)

(f)

progressively increasing normal load

Figure 9: Schematic representation of the scratch channel obtained during scratch tests of hard ceramic coatings: (a) forward chevron tensile cracks, (b) lateral cracks, (c) arc tensile cracks, (d) coating chipping, (e) thin film spalling, (f) coating break-through (based on $[59,64]$.

Scratch tests can be conducted in the following modes: progressive loading (PLST) [52, 55, 65], constant loading (CLST) [52, 65] and multi-pass loading (MPLST) [66-68], which has been gaining popularity in the recent years. Nevertheless, methodology of evaluation of the coating adhesion using the scratch test has been described in numerous standards, e.g. American and Japanese ones, as well as is recommended by the other researchers as a universal and versatile method of measuring the adhesion of the thin films [52]. Currently, the PLST method is widely used both in the R\&D laboratories, as well as in the surface modification industry [52].

As presented in this chapter, there is a vast variety of adhesion measurement methods applicable for hard antiwear coatings. Nevertheless, the most popular adhesion measurement method is currently the scratch test, which has been described in detail in few international standards. When comparing the obtained results with other authors one should, however, take a measure of caution. There are differences between the authors in determin- ing the critical loads. Though standards state that one or two critical loads should be considered, some of the authors associate critical loads e.g. with the cohesive failure of the coating (first symptoms of cracking), adhesive failure (chipping of the coating) and its breakthrough [37]. Though it provides an in-depth analysis of the scratch channel and the phenomena that occur during scratch testing, particular attention has to be paid by other researchers in order not to confuse the critical loads stated in their own research with the loads recommended in standards.

\section{Conclusions}

As presented in the paper, evaluation of hard anti-wear coatings is a complex process which requires careful consideration and experiment planning. In many cases, assessment of the tribological properties of the coating requires altering the existing configuration of the research equipment to the specific needs of the planned product. Due to that, prior to the time- and cost-consuming wear tests, it is reasonable to use generic measurement approaches. Though the measurement techniques proposed in this paper cannot be implemented to substitute an actual wear test, the list of potential coatings can be reduced substantially after successful application of a scratch test or nanoindentation measurements even at an initial stage of research. It is a matter of high importance to understand the causes behind the specific wear mechanisms of the coatings and therefore predict their durability and reliability in actual applications. Selection of the appropriate measurement methods is necessary not only in terms of establishing the coating properties, but also helps to save time and funding resources. It is also a good practice to use the evaluation methods that have been internationally appraised, e.g. by the international standard organizations. As stated in the paper, there are numerous standards deployed for the specific needs of the hard coatings evaluation.

Regarding coating thickness measurement, optical microscopy is widely used for both $R \& D$ process purposes and in the scientific work. As far it is a method that is easy to implement, it does not take into consideration porosity of the coating and, depending on the chosen type of microscope, the measurement can be affected by the resolution of the microscope or even the coating material itself.

During nanoindentation measurements, one should always remember that it is recommended to measure the coating thickness prior to the hardness and Young's modu- 
lus tests, as the indent depth should not exceed maximum $10 \%$ of the coating thickness. It is also desirable to control the surface roughness, but if it is impossible due to specific material requirements, the number of taken measurements should be appropriately increased. What is more, there are difficulties in comparing obtained results with findings obtained by other authors as the method is sensitive to the applied load. Results from nanoindentation measurements are also highly sensitive to the diamond tip bluntening - therefore, after conducting numerous measurements, special attention should be paid to the indenter condition.

Nanoindentation measurements are crucial in the point of view of the wear control. As a result of nanoindentation measurements, values of three ratios can be established: $E / H, E^{3} / H^{2}$, as well as $E_{\text {coating }} / E_{\text {substrate }}$. According to the numerous findings, it is reasonable to pay attention to hardness and Young's modulus of the developed coating, as well as on the mismatch between its Young's modulus and the elastic modulus of the substrate material. In general, the greater the $E / H$ and $E^{3} / E^{2}$ values, the better, while the $E_{\text {coating }}$ to $E_{\text {substrate }}$ ratio has to be controlled with regard to the mechanical properties of the substrate and the coating.

For measurement of adhesion of an anti-wear coating, it is recommended to use e.g. the scratch test method. Despite the possible problems with reproducibility of the findings, it is a fast method to distinguish the coating with the highest adhesion in the group of the obtained films. The great advantage of the scratch test method is also the ability to conduct live scratch channel observations along with the acoustic emission measurements. Based on the recognized failure modes of the coating, damage pattern in actual applications can be predicted.

Acknowledgement: The work was supported by the National Science Center (Republic of Poland) within the PRELUDIUM 13 grant proposal, project no. UMO2017/25/N/ST8/02270. Studies have also been financed from the funds for science of Ministry of Science and Higher Education of Republic of Poland, project no. S/WM/2/2017.

\section{References}

[1] N. M. Jennett and M. G. Gee, Mechanical testing of coatings, In: B. G. Mellor (Ed.), Surface coatings for protectiong against wear, Woodhead Publishing, Cambridge, (2006).

[2] D. M. Mattrox, Non-Elemental Characterization of Films and Coatings, In: P. M. Martin (Ed.), Handbook of Deposition Technologies for Films and Coatings: Science, Applications and Technologies, Elsevier UK, Oxford, (2010).

[3] M. Lindner and M. Schmid, Coatings 7 (2017) 9.

[4] PN-EN ISO 2064:2004 Metallic and other non-organic coatings - Definitions and conventions concerning the measurement of thickness.

[5] M. Kupczyk, P. Cieszkowski, P. Libuda, D. Jakrzewski, Zeszyty naukowe Politechniki Poznanskiej, 2 (2005) 33-41 (in Polish).

[6] L. C. Hernández, L. Ponce, A. Fundora, E. López, and E. Pérez, Materials, 4 (2011) 929-940.

[7] W. Stec, Metoda bezstykowego wyznaczania rezystancji cienkich warstw przewodzacych, Doctoral dissertation, AGH University of Science and Technology, Krakow, (2008) (in Polish).

[8] M. tępicka and M. Grądzka-Dahlke, Acta mechanica et automatica, 10 (2016) 150-158.

[9] P. Hermanowicz, J. Smolik, and J. Bujak, Problemy eksploatacji Maintenance problems, 4 (2010) 47-57.

[10] K. Holmberg and A. Matthews, Coatings Tribology - Properties, Mechanisms, Techniques and Applications in Surface Engineering, Elsevier B.V., Amsterdam, (2009).

[11] M. Tkadletz, N. Schalk, R. Daniel, J. Keckes, Ch. Czettl, and Ch. Mitterer, Surf. Coat. Technol., 285 (2016) 31-46.

[12] W. C. Oliver and G. M. Pharr, J. Mater. Res., 7 (1992) 1564-1583.

[13] H. Li and J. J. Vlassak, J. Mater. Res., 24 (2009) 1114-1126.

[14] W. C. Oliver and G. M. Pharr, J. Mater. Res., 19 (2004) 3-20.

[15] A. C. Fischer-Cripps, Nanoindentation, Springer-Verlag New York, (2011).

[16] E. Dryzek, Badania warstwy wierzchniej w aluminium i stopach aluminium za pomocą anihilacji pozytonów i metod komplementarnych, PhD thesis, Krakow, (2008) (in Polish).

[17] G. M. Pharr and A. Bolshakov, J. Mater. Res., 17 (2002) 26602671.

[18] I. N. Sneddon, Int. J. Eng. Sci., 3 (1965) 47-57.

[19] G. M. Pharr, W. C. Oliver, and F. R. Brotzen, J. Mater. Res., 7 (1992) 613-617.

[20] R. B. King, Int. J. Solids Struct., 23 (1987) 1657-1664.

[21] M. Asgari, A. Barnoush, R. Johnsen, and R. Hoel, Mater. Sci. Eng. A., 529 (2011) 425-434.

[22] ISO 14577-1:2015 Metallic materials - Instrumented indentation test for hardness and materials parameters - Part 1: Test method.

[23] Y. Li, P. Valvala, S. Watcharotone, and L. C. Brinson, J. Mater. Res., 30 (2015) 1747-1760.

[24] W. Ni and Y. T. Cheng, J. Mater. Res., 20 (2005) 521-528.

[25] J. Solis, H. Zhao, C. Wang, J. A. Verduzco, A. S. Bueno, and A. Neville, Appl. Surf. Sci., 383 (2016) 222-232.

[26] V. Gorokhovsky, C. Bowman, P. Gannon, D. VanVorous, A. A. Voevodin, A. Rutkowski, C. Muratore, et al., Surf. Coat. Tech., 201 (2006) 3732-3747.

[27] A. Leyland and A. Matthews, Wear, 246 (2000) 1-11.

[28] A. Matthews, S. Franklin, and K. Holmberg, J. Phys. D, 40 (2007) 5463-5475.

[29] B. D. Beake, G. A. Bell, S. R. Goodes, N. J. Pickford, and J. F. Smith, Surf. Eng. 26 (2010) 37-49.

[30] S. Zimowski, Tribologia, 4 (2014) 149-160.

[31] W. Ni, Y. T. Cheng, M. J. Lukitsch, A. M. Weiner, and L. C. Lev, Appl. Phys. Lett., 85 (2004) 4028-4030.

[32] W. Ni, Y. T. Cheng, C. M. Cheng, and D. A. Grummon, J. Mater. Res., 19 (2004) 149-157.

[33] J. Musil and M. Jirout, Surf. Coat. Tech., 201 (2007) 5148-5152. 
[34] J. Musil, R. Novak, R. Cerstvy, Z. Soukup, and J. Vac., Sci. Tech. A, 28 (2009) 244-249.

[35] X. Huang, I. Etsion, and T. Shao, Wear, 54 (2015) 338-339.

[36] J. C. Avelar-Batista, R. D. Mancosu, J. Morais, and A. Matthews, Plasma nitriding and PAPVD hard coatings: a critical overview of duplex coating processing, Bariloche, Argentina: Jornadas SAM/CONAMET Conference, (2003), pp. 600-603.

[37] M. Łępicka, M. Grądzka-Dahlke, D. Pieniak, K. Pasierbiewicz, and A. Niewczas, Wear, 62 (2017) 382-383.

[38] C. Wang, K. Shi, C. Gross, J. M. Pureza, M. M. Lacerda, and Y. W. Chung, Surf. Coat. Tech., 257 (2014) 206-212.

[39] Z. Chen, K. Zhou, X. Lu, and Y. Ch. Lam, Acta Mechanica, 225 (2014) 431-452.

[40] A. H. Choi, B. Bem-Nissam, A. Bendavid, and B. Latella, Mechanical behavior and properties of thin films for biomedical applications, In: H. J. Griesser (Ed.), Thin Film Coatings for Biomaterials and Biomedical Applications, Elsevier, (2016).

[41] J. Domińczuk, Postępy nauki i techniki, 9 (2011) 28-37 (in Polish).

[42] W.-S. Kim, I.-H. Yun, J.-J. Lee, and H.-T. Jung, Int. J. Adhes. Adhes., 30 (2010) 408-417.

[43] J. Takadoum and H. H. Bennani, Surf. Coat. Tech., 96 (1997) $272-$ 282.

[44] P. Lu, H. Gomez, X. Xiao, M. Lukitsch, D. Durham, A. Sachdeve, et al., Surf. Coat. Tech., 215 (2013) 272-279.

[45] S. Sveen, J. M. Andersson, R. M’Saoubi, M. Olsson, Wear 308 (2013) 133-141.

[46] R. Ali, M. Sebastiani, and E. Bemporad, Mater. Des., 75 (2015) 47-56.

[47] B. Ramamoorthy and B. C. Yeldose, Intell. Infor. Manag., 1 (2009) 179-194.

[48] R. Lacombe, Adhesion Measurement Methods: Theory and Practice, CRC Press, Boca Raton, (2005).

[49] L.-M. Berger, Coatings by Thermal Spray, In: K. S. Vinod, D. Mari, and L. Llanes (Eds.), Comprehensive hard materials: Volume 1 Hardmetals, Elsevier Ltd., (2014).

[50] P. G. Charalambides, J. Lund, A. G. Evans, and R. M. McMeeking, J. Appl. Mech., 56 (1989) 77-82.
[51] Z. Suo and J. W. Hutchinson, Mater. Sci. Eng., A107 (1989) 135143.

[52] P. Kutilek and J. Miksovsky, Acta Bioeng. Biomech., 13 (2011) 87-94.

[53] K. Zhou, Z. Chen, and H. J. Hoh, Characterization of Coating Adhesion Strength, In: S. Zhang (Ed.), Thin Films and Coatings: Toughening and Toughness Characterization, CRC Press, Boca Raton, (2016).

[54] A. Ghabchi, S. Sampath, K. Holmberg, and T. Varis, Wear, 313 (2014) 97-105.

[55] K. Chronowska-Przywara and M. Kot, Tribologia 2 (2014) 19-29.

[56] J. S. Bull and E. G. Berasetegui, Tribol. Int., 39 (2006) 99-114.

[57] P. Hedenqvist and S. Hogmark, Tribol. Int., 30 (1997) 507-516.

[58] N. Schwarzer, Q.-H. Huong, N. Bierwisch, G. Favaro, M. Fuchs, P. Kempe et al., Surf. Coat. Tech., 206 (2011) 1327-1335.

[59] K. Holmberg, A. Laukkanen, H. Ronkainen, K. Wallin, and S. Varjus, Wear, 254 (2003) 278-291.

[60] G. Pagnoux, S. Fouvry, M. Peigney, B. Delattre, and G. MermazRollet, Mechanical behavior of DLC coatings under various scratch conditions, International Conference on Fracture Fatigue and Wear, Sep 2014, Kyushu, Japan, (2014), hal-01093241.

[61] J. Yang, J. J. Roa, M. Oden, M. P. Johansson-Joesaar, J. Esteve, and L. Llanes, Surf. Coat. Tech., 265 (2015) 174-184.

[62] R. Viana, M. S. F. de Lima, W. F. Sales, W. M. da Silva Jr., and A. R. Machado, Surf. Coat. Tech., 276 (2015) 485-501.

[63] J. S. Bull, Trib. Int., 30 (1997) 491-498.

[64] ASTM C1624-05(2015) Standard Test Method for Adhesion Strength and Mechanical Failure Modes of Ceramic Coatings by Quantitative Single Point Scratch Testing.

[65] M. Barletta, V. Tagliaferri, A. Gisario, and S. Venetacci, Tribol. Intern., 64 (2013) 39-52.

[66] M. Anand, G. Burmistoviene, I. Tudela, R. Verbickas, G. Lowman, and Y. Zhang, Wear, 39 (2017) 388-389.

[67] S. Kataria, N. Kumar, S. Dash, R. Ramaseshan, and A. K. Tyagi, Surf. Coat. Tech., 205 (2010) 922-927.

[68] G. A. Rodríguez-Castro, R. C. Vega-Moron, A. Meneses-Amador, H. W. Jimenez-Diaz, J. A. Andraca-Adame, I. E. Campos-Silva et al., Surf. Coat. Tech., 307 (2016) 491-499. 